\title{
Special issue: innovation, communication and engineering 2018
}

\author{
Sheng-Joue Young ${ }^{1} \cdot$ Ajit Khosla $^{2}$
}

Published online: 22 October 2021

(C) The Author(s), under exclusive licence to Springer-Verlag GmbH Germany, part of Springer Nature 2021

Innovation, Communication and Engineering 2018 covered a wide range of topics, including information science, innovation design, industrial design, applied mathematics, computer science, cultural and creative research, electrical and electronic engineering, mechanical engineering, automation engineering, green technology and architectural engineering, material science, and other related fields. This special issue presented more than 45 excellent papers that covers a wide range of fundamental studies, industrial practices, and engineering innovations by applying knowledge on microsystems. Engineering and design innovations are academic and practical engineering fields that involve systematic technological materialization through scientific principles and engineering designs. Technological innovation through electrical/mechanical engineering includes information technology-based (IT) intelligent electrical/mechanical systems, electronics, mechanics, human-computer interactions, and design innovations. IT-based intelligent systems, which may implant intelligence to systems, is an interdisciplinary area combining conventional electrical/mechanical technology and new IT. The Internet of Things (IoT) has also gained popularity in recent years. This special issue collected many IoT-related studies, such as those on sensors, electronics, software, and connectivity, which enabled objects to connect and exchange data.

All articles in this issue underwent rigorous peer reviews, which are conducted by Microsystem Technologies. The acceptance of this special issue was based on recommendations of the reviewers, mandatory revisions, final examinations, and reviews conducted by guest editors. This publication is expected to be a key issue for Microsystem Technologies.

The guest editors would like to thank the authors for their contributions and all reviewers for their constructive comments. Finally, we would like to thank the editorial team for their work in making this special issue a success.

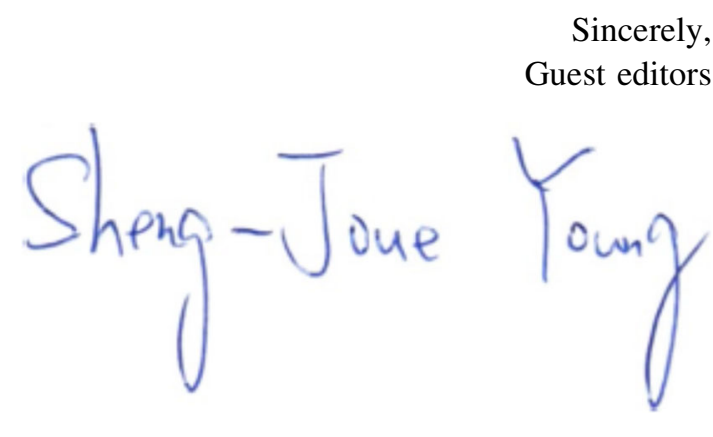

Prof. Ajit Khosla

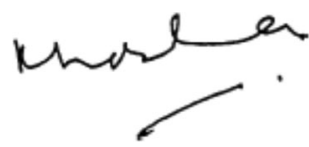

Publisher's Note Springer Nature remains neutral with regard to jurisdictional claims in published maps and institutional affiliations.

Sheng-Joue Young

shengjoueyoung@gmail.com

Ajit Khosla

khosla@gmail.com

1 Department of Electronic Engineering, National United University, Miaoli 36063, Taiwan

2 Faculty of Engineering, Yamagata University, 4-3-16 Jonan, Yonezawa, Yamagata 992-8510, Japan 